\title{
The Effect Of A Pseudotransformational Leader: Whitewater Rafting In A Hurricane
}

\author{
Janice M Spangenburg, Ph.D., USA
}

\begin{abstract}
Leadership is a long studied and interesting topic. As more thinking occurs with regard to different types and flavors, leadership sense-making is something that is done all the time. With this regard, such concepts come to light and often capture and incite our interest and appeal to the situation we are experiencing at the time. This is where we take the concept and reality of pseudo-transformational leadership. Pseudo-transformational leadership is less than authentic and can occur at any time and have a lasting negative outcome. When it is experienced, it can appear as a sudden change in an organizational event or a wind of change that doesn't rear its ugly intention at the time of occurrence. This article will take the reader on a journey of what can occur and how to lean with the gut feeling. It can be a true way of knowing what decisions to make and how to adapt and recover for such change. The metaphor is used as a whitewater raft to paint a visual picture of how this can affect and change an experience from a good or semi-good one to a horrible one, or at least one that is less than tasteful. This can also involve leadership style and behavior and can cause and exacerbate organizational conflict, as can we evidenced through the outcome of this case.
\end{abstract}

Keywords: Organizational Change; Organizational Conflict; Leadership Styles; Leadership Behavior

\section{OVERVIEW}

experience a number of leadership styles in our working careers and behaviors of leaders that seem
to err in our minds because of what our values and traditions have taught us, especially when we
know in our core what is expected and what is the norm. However, we are in a time where we have to adapt and act quickly and accordingly. Sometimes telling a story and developing a metaphor can help in the healing process after a bad experience. When we are confronted with a situation that requires healing and purging, the experience using an analogy can sometimes put us in a better place and mindset. The author chooses to use an activity that depicts how she feels as a result of the effect of pseudo-transformational leadership. This is counter to authentic transformational leadership which must be grounded in moral foundations (Bass and Steidlmeier, 1999).

Whitewater rafting is a thrilling, exhilarating, and challenging event and offers a refreshing voyage through some curves and water rushes and falls, and the like. This can be both a thrill and very scary, but just imagine how this would be juxtaposed with a hurricane with severe gale force winds and rain. This is the dance with the pseudotransformational leader. It is a dance that really has no meaning or purpose and it leaves us upset and disorganized as if we were just stung by a giant bee. We just don't understand it and we can't make sense of it.

Organizations today tremendously and constantly change. New demands and requirements necessitate this and can bring a host of things to the forefront every day and take more time to handle these competing demands on any given day. This requires patience and perseverance on the part of employees, and leaders also have to be of a certain type and quality. Even the best leaders can succumb to all of the changes, conflicts, and challenges. Sometimes the tasks and the environment of an organization can be enough on any given day. The culture can also sometimes be difficult as well, but if the leadership is supportive and guides the organization and team forward, it is just what takes the edge off of everything; at least that is what the author thought all these years as a consultant and an employee in her career and with her past experiences. All this brings us to a point where we question, "What exactly is our purpose, why were we placed here, and what lesson are we to learn?" 
The joys of having a supportive and positive leader are few and far between in our careers and then at pivotal points, we are confronted with changes and situations that cause us to scratch our heads and wonder. We have to lean on the more positive leadership experiences to help us get through the trying times of conflict. While these lessons are needed to prepare us for the more challenging situations to come, they are nevertheless very disenheartening. Sometimes we are not aware that a leader is not what he/she claims to be until we experience the actions over time. This individual is different but sings a song that sounds pleasant to the ears, such as the sirens that Homer heard in the epic poem (1976). A good flowing positive culture can soon be very dark and oppressive as a result of the wielding of this leader's perception, personality, and actions that are so far away from good that it makes one shudder. This so-called 'leader' comes in with a hidden agenda. This can be tempting and even believable, but we have to be cautious in every way. This person wears a disguise, but when the mask is taken off, we see the real deal, which is not pretty. One of the characteristics of this type of individual is non-responsiveness to any type of communication. In fact, this leader does not value the true foundation of communication and is "above" anyone else, therefore feeling that communication is not necessary. The focus is on the self and it is all about that one person - not you or us. They have a very bad attitude under the surface, but it is hidden on the surface. They cloak real intentions and attack without warning.

\section{CONCLUSION}

This is all troublesome and can weaken even the most solid and vibrant structure and can be deadly to culture and the ability to thrive and perform. Motivation is dismissed and loyalty is not a commonplace theme. Having this kind of leader is a disease that goes into the organization like an epidemic and causes rife with uncertainty, discontent, and demise. This takes the organization into peril and demise and can annihilate it unless something is done quickly. Moreover, this leader goes right for the jugular and takes one's thunder and excitement away before they even realize it.

What has been learned is that we all have that "gut feeling" and when one says something feels wrong, it truly is. The author recommends that if this ever happens, take cover and protect yourself against the spoils of the disaster. Another reality is that when the person is gone, the knowledge and input is lost, leaving a gaping hole in the organization which can last a long time. The organization cannot recover in part or in full when that occurs.

\section{AUTHOR INFORMATION}

Dr Spangenburg spent over 24 years in the military and federal government working with all five services. Dr Spangenburg has led two successful management consulting practices and has served on the Board of Directors for Union and mentors, and she advises government organizations. Dr. Spangenburg has held various positions in higher education, both administrative and teaching, for over 18 years; has been very involved with both graduate and undergraduate courses, including teaching and mentoring; and has led the way for transformative and innovative educational products for academic institutions in degree programs on every academic level. E-mail: drjanices@msn.com 757-650-4956

\section{REFERENCES}

1. Bass, B. M., \& Steidlmeier, P. (1999). Ethics, character, and authentic transformational leadership behavior. The Leadership Quarterly, 10(2), 181-217

2. Beye, Charles (1976). The Iliad and the Odyssey-and the epic tradition. New York: Gordian Press. 